\title{
Intergradation between discrete lineages of Tevnia jerichonana, a deep- sea hydrothermal vent tubeworm
}

\author{
Haibin Zhang ${ }^{\mathrm{a}, \mathrm{b}^{*}}$, Shannon B. Johnson ${ }^{\mathrm{a}}$, Vanessa R Flores ${ }^{\mathrm{a}, \mathrm{c}}$, and Robert C Vrijenhoek ${ }^{\mathrm{a}}$ \\ ${ }^{a}$ Monterey Bay Aquarium Research Institute, Moss Landing, CA, USA \\ ${ }^{\mathrm{b}}$ Present address: Sanya Institute of Deep-Sea Science and Engineering, Chinese \\ Academy of Sciences, Sanya, China, 572000 \\ ${ }^{\mathrm{c}}$ Present address: 385 Life Sciences Addition, UC Berkeley, Berkeley, CA 94720
}

Corresponding author: Tel.: (+86) 898-88380935 (o).

Email address: hzhang@ sidsse.ac.cn (Haibin Zhang)

\begin{abstract}
We describe a broad zone of intergradation between genetically differentiated, northern and southern lineages of the hydrothermal vent tubeworm, Tevnia jerichonana. DNA sequences from four genes, nuclear HSP and ATPs $\alpha$ and mitochondrial COI and $C y t b$ were examined in samples from eastern Pacific vent localities between $13^{\circ} \mathrm{N}$ and $38^{\circ} \mathrm{S}$ latitude. Allelic frequencies at these loci exhibited concordant latitudinal clines, and genetic differentiation (pairwise $\Phi_{\mathrm{ST}}$ 's) increased with geographical distances between sample localities. Though this pattern of differentiation suggested isolation-by-distance (IBD), it appeared to result from hierarchical population structure. Genotypic assignment
\end{abstract}


Zhang et al. manuscript for Rona volume

tests identified two population clusters comprised of samples from the northern East Pacific Rise (NEPR: 9-13 ${ }^{\circ} \mathrm{N}$ ) and an extension of the Pacific-Antarctic Ridge (PAR: $31-$ $32^{\circ} \mathrm{S}$ ) with a zone of intergradation along the southern East Pacific Rise (SEPR: $7-17^{\circ}$ S). The overall degrees of DNA sequence divergence between the NEPR and PAR populations were slight and not indicative of lengthy isolation. Bayesian assignment methods suggested that the SEPR populations constitute intergrades that connect the NEPR and PAR populations. Though it typically is difficult to distinguish between primary and secondary intergradation, our results were consistent with parallel studies of vent-restricted species that suggest a high degree of demographic instability along the superfast-spreading SEPR axis. Frequent local extinctions and immigration from NEPR and PAR refugia probably shaped the observed pattern of intergradation.

Keywords: Intergrade zone, Tevnia jerichonana, Annelida, Polychaeta, Siboglinidae, Hydrothermal vent. 
Zhang et al. manuscript for Rona volume

We dedicate this paper to the memory of Professor Peter Rona, a valued colleague and participant in the SEPR-1999 expedition that sampled many of the specimens examined in this and related studies of hydrothermal vent organisms.

\section{Introduction}

Clines, or geographical gradients in the characteristics of species (Huxley, 1938), can result from adaptive differentiation (primary intergradation) or from the reconnection of genetically differentiated populations (secondary intergradation). The causes are difficult to distinguish, however, in the absence of historical biogeographic information (Endler, 1977, 1982). Examinations of multi-gene data can help to distinguish the causes because primary intergradation is unlikely to generate coincident clines among multiple independent genes, whereas secondary intergradation commonly produces parallel clines (Barton, 1983). Recent secondary intergradation also tends to generate linkage disequilibria among independent genes (Barton and Hewitt, 1985). These patterns have been used to investigate dynamic processes affecting hybrid zones and intergradation in a wide variety of fresh-water and terrestrial plants and animals (reviews in Harrison, 1993; Arnold, 1997). Marine examples are less numerous, however, and mostly limited to commercially important, near-shore taxa (Gardner, 1997).

Only two hybrid zones are known from mid-ocean environments, and both involve deep-sea hydrothermal vent mussels. Bathymodiolus azoricus and B. puteoserpentis contact one-another and hybridize at an intermediate locality on the Mid-Atlantic Ridge (MAR) (O'Mullan et al., 2001; Won et al., 2003b). Bathymodiolus thermophilus and B. antarcticus contact one another along the western flank of the Easter Microplate, a 
tectonic feature at the southern terminus of the East Pacific Rise (EPR) (Johnson et al., 2013). Both of the hybrid zones exhibit parallel step-clines for multiple genes and significant linkage disequilibria among mitochondrial haplotypes and nuclear genes. Thus, they meet expectations for "tension zones" that are maintained by recent immigration of the parental lineages and possibly "hybrid unfitness" (Barton and Hewitt, 1985). The two hybrid zones occur in geographical regions of low overall fitness for mussels. Demographic sinks, such as these, can focus and stabilize hybrid zones (Barton, 1980)

Here we report a third example, involving multilocus step-clines and intergradation between metapopulation segments of the Jericho tubeworm, Tevnia jerichonana (Annelida: Polychaeta: Siboglinidae, Fig. 1). These small to mid-sized worms are pioneers that rapidly colonize nascent and re-activated, low-temperature vents $\left(2-100^{\circ} \mathrm{C}\right)$ along the East Pacific Rise (Jollivet, 1993), where they are quickly replaced by the giant siboglinid, Riftia pachyptila (Shank et al., 1998; Mullineaux et al., 2000; 2012). As opposed to R. pachyptila (Fig. 1 in Coykendall et al., 2011), the short persistence times of T. jerichonana results in a spotty distribution of extant colonies along the EPR (Fig. 2A). Details about its dispersal potential are not known, but we can refer to pioneering study of $R$. pachyptila as a model (Marsh et al., 2001). The giant siboglinid produces trochophore larvae that develop for about 28 days before metamorphosis and settlement. With prevailing currents, $R$. pachyptila's larval duration is expected to result in mean dispersal distances of about $100 \mathrm{~km}$. However, T. jerichonana appears to have greater realized dispersal, because estimates of gene flow tend to be higher $(\mathrm{Nm}>25)$ than those of $R$. pachyptila $(5 \leq N m<25)$ (Vrijenhoek, 2010). A study of mitochondrial (mt) DNA 
variation in $T$. jerichonana revealed an isolation-by-distance (IBD) signal - i.e. genetic differentiation $\left(F_{\mathrm{ST}}\right)$ that increases with geographical distances between vents (Hurtado et al., 2004; Audzijonyte and Vrijenhoek, 2010). Nonetheless, the IBD-like pattern does not necessarily indicate an underlying process of "isolation-by-distance" (sensu Wright, 1943). Other processes including adaptive divergence, range expansions, hierarchical subdivision, introgressive hybridization, and sparse sampling can produce similar patterns (Meirmans, 2012; Orsini et al., 2013). To determine if the IBD-like signal is unique to mtDNA or more pervasive, we compared genetic structures revealed by fragments of two independent nuclear genes, ATP synthetase subunit $\alpha$ (ATPs $\alpha)$ and heat-shock protein $(H S P)$, with those of two mitochondrial genes, cytochrome- $c$-oxidase subunit I (COI), and cytochrome B (Cytb).

\section{Methods}

\subsection{Sample collection and identification}

Samples were collected between 1998 and 2005 during expeditions conducted along NEPR, SEPR, PAR, and GAR segments of the southeastern Pacific ridge systems (Fig. 2A). We explored 20 disjunct hydrothermal vent fields with the human occupied vehicle (HOV) Alvin (Woods Hole Oceanographic Institution). The present specimens were sampled from seven locations (Table 1). The worms typically occur in dense clusters that could be grasped with HOV Alvin's manipulator arms and deposited in an insulated box containing ambient seawater. Upon recovery at the surface, whole worms were stored in $2^{\circ} \mathrm{C}$ filtered seawater prior to tissue sampling. A small sample of vestimentum, a tissue normally devoid of endosymbiotic bacteria, was frozen at $-70^{\circ} \mathrm{C}$ or preserved in $95 \%$ EtOH. 
Tevnia jerichonana commonly co-occurs with two other siboglinid tubeworms, Riftia pachyptila and the Oasisia species complex. Adults are easily distinguished macroscopically. Riftia pachyptila are large (typically $>1 \mathrm{~m}$ long) robust worms with a long, brilliant red, anterior plume (obturaculum) and a smooth-walled flexible tube. Tevnia jerichonana and Oasisia species are smaller, thin-bodied worms with a short obturaculum. Tevnia tubes are rigid and relatively straight with closely spaced external flanges. Oasisia tubes are thinner and more flexible with widely spaced, large, external flanges. Very young, post-settlement juveniles of Oasisia, R. pachyptila, and $T$. jerichonana were difficult to distinguish macroscopically. All T. jerichonana specimens used in this study were distinguished by their unique mitochondrial $C O I$ sequences (Black et al., 1997; Hurtado et al., 2004).

\subsection{Gene sampling, DNA extraction and sequencing}

Genomic DNA was extracted using the microplate extraction method of Elphinstone et al. (2003), excepting that we used $100 \mu \mathrm{L}$ of lysed tissue and $100 \mu \mathrm{L}$ of elution buffer. Mitochondrial $C O I$ and $C y t b$ were amplified with DNA primers previously known to work with siboglinids (Table 2). Amplifications were conducted with Amplitaq Gold® Fast PCR Master Mix, UP (Life Technologies Corp., Carlsbad, CA). Initial denaturation occurred at $95^{\circ} \mathrm{C}$ for $10 \mathrm{~min}$, followed by 35 cycles of $94^{\circ} \mathrm{C}$ for $1 \mathrm{~min}, 55^{\circ} \mathrm{C}$ for $1 \mathrm{~min}$, and $72^{\circ} \mathrm{C}$ for $2 \mathrm{~min}$, with a final extension at $72^{\circ} \mathrm{C}$ for $7 \mathrm{~min}$.

To identify nuclear gene markers, we screened DNA primers previously reported to amplify the genes from invertebrate animals (Jarman et al., 2002; Audzijonyte and Vrijenhoek, 2010; Coykendall et al., 2011). Inconsistent amplifications and inclusions of one or more introns that produced unscorable length polymorphisms in the heterozygotes 
led to the exclusion of many candidate genes. Fragments of two nuclear genes, ATPs $\alpha$ and $H S P$, provided consistently scorable polymorphisms (Table 2). Due to weak initial amplifications, we designed nested primers to conduct secondary amplifications for both genes. Primary amplifications of ATPs $\alpha$ were conducted with published primers (Jarman et al., 2002), and secondary amplifications were conducted with newly designed internal primers specific to $T$. jerichonana. The $H S P$ primers were newly designed from GenBank sequences for HSP-70 for T. jerichonana (FN86147-8). The primer HSP242F1 was anchored in HSP-70 exon-1; sequences spanned intron 1, and the primer HSP922R1 was anchored in $H S P-70$ exo-2. Translated protein sequences were compared with GenBank protein sequences to ensure that the correct product was analyzed. Primary and secondary amplification mixtures contained $1-2 \mu \mathrm{L}$ of DNA template, $12.5 \mu \mathrm{L}$ AmpliTaq Gold ${ }^{\circledR}$ Fast PCR Master Mix (Life Technologies, Grand Island, NY), and $1 \mu \mathrm{L}$ of each primer at $10 \mathrm{umol} / \mu \mathrm{L}$, for a total of $25 \mu \mathrm{L}$. PCR conditions were $95^{\circ} \mathrm{C}$ for $10 \mathrm{~min}$, followed by 35 cycles of 3 s denaturing at $96^{\circ} \mathrm{C}, 3 \mathrm{~s}$ annealing at $56^{\circ} \mathrm{C}$, and $15 \mathrm{~s}$ extension at $68^{\circ} \mathrm{C}$, with a final extension at $72{ }^{\circ} \mathrm{C}$ for $7 \mathrm{~min}$.

PCR products were purified using a Multiscreen HTS PCR 96 vacuum manifold system (Millipore Corp. Billerica, MA), then resuspended in $50 \mu 1$ of sterile water. DNA sequencing employed the same PCR primers. Purified PCR products were sequenced bidirectionally on an ABI 3100 capillary sequencer using BigDye terminator chemistry (Applied Biosystems Inc., Foster, CA). All sequences were edited and manually aligned in GenEIOUS 8.0.4 (http://www.geneious.com, Kearse et al., 2012)").

\subsection{Statistical analyses}

Haplotypes for the mitochondrial fragments were inferred directly from sequence 
traces, whereas those for the nuclear gene fragments were reconstructed using the program PHASE v. 2.1 (Stephens et al., 2001). Haplotype networks were constructed with the median-joining (MJ) method implemented in NETWORK v. 4.612 (Bandelt et al., 1999). GENEPOP v3.4 (Raymond and Rousset, 1995) was used to conduct exact tests of Hardy Weinberg equilibrium (HWE) and linkage disequilibrium (LD) for the nuclear loci. We used CNDW (Asmussen and Basten, 1994; Basten and Asmussen, 1997) to test for cytonuclear disequilibrium between the mtDNA and the nDNA genotypes. The branch and bound method (with the default parameters) as implemented in BEAGLE (Lyngsø et al., 2005) was used to reconstruct a genealogical history of recombination for each locus. We used LOSITAN to test each locus for selection. Simulations included $10,000-40,000$ replications to estimate the neutral mean $F_{S T} 95 \%$ confidence intervals under an infinite allele mutation model. Confidence intervals of simulated values were then plotted with empirical values to determine if they were outside of the expected ranges, indicating selection (Beaumont and Nichols, 1996; Antao et al., 2008). We used ARLEQUIN 3.5 (Excoffier and Lischer, 2009) to estimate $H$ (haplotype), $\pi$ (nucleotide) diversity indices, and $\Phi_{\mathrm{ST}}$ values, and to conduct hierarchical AMOVAs. Estimates of allelic richness $\left(a^{\prime}\right)$ were obtained by the rarefaction methods implemented in HP-RARE v. 10 (Kalinowsky, 2005).

To infer the patterns of population structure without prior knowledge of geomorphological partitioning, we conducted assignment tests with STRUCTURE v. 2.3 (Pritchard et al., 2000). Haplotypes for each of the four genes were treated distinct alleles $\left(a^{1}, a^{2}, \ldots a^{n}\right)$, and a multilocus genotype (MLG) was constructed for each individual. Analyses were first conducted separately for the mitochondrial and nuclear genotypes. 
Then, the two haploid mitochondrial genes were concatenated and combined with the two diploid nuclear genotypes. We reported results of the concatenated data because both analyses yielded identical results. The STRUCTURE analyses were conducted for values of $K$ (number of population clusters) ranging from 1 to 7 , using an admixture model and sampling locations as prior conditions (LOCPRIOR=1). Analyses were iterated ten times for each value of $K$ with correlated allele frequencies. The first $10^{4}$ generations (burn-in) of each iteration were discarded, and $10^{6} \mathrm{MCMC}$ generations were used to estimate the optimum value for $K$ by the delta $K$ method of Evanno et al. (2005).

We conducted Bayesian assignment methods with BAYESASS v.3 (Wilson and Rannala, 2003) and NEwHYBRIDS (Anderson and Thompson, 2002) to estimate ancestries and immigration rates. The BAYESASS method does not assume Hardy-Weinberg equilibrium, which is appropriate in cases that exhibit heterozygote deficiencies and linkage disequilibrium. Analyses were conducted with two populations (EPR and PAR) for $10^{7-8}$ iterations and sampled every 2000 generations following a burn-in of $10^{6}$. We seeded the iterations with random numbers, and used default mixing parameters of 0.3 for allele frequencies and 0.5 for the inbreeding coefficient. The Bayesian deviances for each run were plotted and calculated to determine the best results to analyze (Meirmans, 2014). STRUCTURE and BAYESASS results were visualized with GGPLOT2 in R. (Wickham, 2009).

To test for isolation-by-distance (IBD), we examined correlations $(r)$ between genetic (G) and geographical distance (D) matrices. The G-matrix was based on pairwise $\Phi_{S T}$ values, estimated with ARLEQuin. The program GenoDive v. $2.0 \mathrm{~b} 23$ (Meirmans and van Teineren, 2004) was used to generate pairwise geographical distances from the geographical coordinates of samples (Table 1) and to estimate Mantel's $r$ between the $\mathbf{G}$ 
and D-matrices. Because the previous AMOVAs supported hierarchical population structure, we assigned the individuals samples to NEPR, SEPR, and PAR subdivisions and applied stratified Mantel tests. This procedure randomly permutes samples within the strata to test the significance of correlations between the $\mathbf{G}$ - and $\mathbf{D}$-matrices.

\section{Results}

\subsection{Genetic diversity}

DNA sequences from four gene fragments were used for the present analyses. Mitochondrial COI (775 bp) and Cytb (320 bp) fragments both exhibited 12 polymorphic sites that distinguished 15 and 12 haplotypes, respectively. A relatively short fragment (173 bp) of nuclear HSP spanned a 98-bp intron and a 75-bp exon region. Six of the ten polymorphic sites were located in the exon region, three of which resulted in amino acid substitutions. The first, involving a $2^{\text {nd }}$-position change (bp 11: $\mathrm{C} \rightarrow \mathrm{T}:$ Proline $\rightarrow$ Leucine), occurred in three individuals. The second, involving a $1^{\text {st }}$-position change (bp 58: $\mathrm{G} \rightarrow \mathrm{A}$ : Glutamic acid $\rightarrow$ Lysine), occurred in five individuals. The third, involving a $2^{\text {nd }}$-position change (bp 62: $\mathrm{C} \rightarrow \mathrm{T}:$ Alanine->Valine), occurred in two individuals. Together these substitutions allowed us to distinguish 20 haplotypes. The intron-spanning fragment of nuclear ATPs $(281 \mathrm{bp}$ ) was the least polymorphic of the four gene fragments, with seven polymorphic sites that distinguished eight haplotypes. None of the loci showed any evidence of selection (data not shown). All DNA sequences and alignments were deposited with GenBank (acc. nos. KM270879-KM271776).

Haplotype networks were generated for each gene fragment (Fig. 3). The COI, Cytb 
and ATPs $\alpha$ networks exhibited similar star-like phylogenies dominated by two sequences (allelic haplotypes *1 and *2). In each case, only one (ATPs $\alpha)$, two (COI), or three (Cytb) mutational steps separated the leading haplotypes. $C O I$ exhibited ten singletons and three rare variants (i.e. $\left.q_{i} \leq 0.05\right)$. $C y t b$ exhibited three singletons, nine rare variants, and one minor variant $\left(q_{i}=0.08\right)$. ATPs $\alpha$ exhibited only one singleton and five rare variants. Genealogical tests for recombination with branch-and-bound method detected no evidence for recombination within these genes. We also tested for recombination between $C O I$ and $C y t b$, and as expected for mitochondrial genes, found no evidence for recombination.

The HSP network was more complex (Fig. 3C). The $H S P^{*} 1$ allele dominated the sample $\left(q_{i}=0.41\right)$, four additional alleles $\left(H S P^{*} 2, * 3, * 4\right.$ and $\left.* 5\right)$ occurred at moderate frequencies $\left(q_{i}>0.05\right)$, eleven were rare $\left(q_{i} \leq 0.05\right)$, and four were singletons. The network exhibited considerable homoplasy (multiple mutation paths connecting the haplotypes). Because HSP genes are highly duplicated in some marine invertebrates (Zhang et al. 2012), we cannot discount that the homoplasy resulted from paralogous genes. Alternatively, if the observed $H S P$ variation resulted from homologous alleles, homoplasy might result from intra-genic recombination. A test using the branch-andbound method detected possible recombination events at five nucleotide sites, four of which were located in the intron region of the amplicon. The putative recombinants are distributed throughout the depth of the genealogy (Supplemental Fig. 1), and thus do not appear to be products of recent secondary contact and hybridization.

Significant heterozygote deficiencies existed for the nuclear genes ( $F_{\text {IS }}$ in Table 3$)$, but the deficiencies do not necessarily signify deviations from random mating. True 
heterozygotes commonly exhibit allelic dropouts due to mutations in the primer sites, low copy number DNA targets, differential methylation of alleles, and consequences of longterm tissue storage (e.g., Piyamongkol et al., 2003). Though we cannot exclude other technical problems, we found that the random mating hypothesis was supported by tests for linkage disequilibrium (LD) between HSP and ATPs $\alpha$. Only one of the seven samples (N9) exhibited a significant LD-test $(P=0.029)$. Tests for cytonuclear disequilibrium (CND) between $H S P$ and mitochondrial $C O I$ or $C y t b$ were not significant in any of the population samples. However, three CND-tests for genotypic disequilibrium involving ATPs $\alpha$ were marginally significant in SEPR samples: with COI in S7 $(P=0.041)$, and with $C y t b$ in $\mathrm{S} 7(P=0.045)$ and in $\mathrm{S} 17(P=0.042)$ samples. As subsequently discussed, cytonuclear disequilibrium is commonly observed in admixed populations.

Allelic frequencies exhibited latitudinal clines. For each locus, frequencies of the leading 'northern' alleles (colored blue in Fig. 2B) decreased in a southward progression, whereas the corresponding 'southern' alleles (white) increased. Slopes for the latitudinal clines were statistically significant and broadly congruent (Fig. 4A). Regionally limited alleles also complemented the clines. For example, some alleles (light blue and green, Fig. 2B) were mostly limited to the NEPR region, whereas other alleles (magenta, pink and orange, Fig. 2B) were most frequent in the PAR region. Private alleles (black) occurred in all samples except the northern most (N9 and N13), and singletons (yellow) occurred throughout the sampled range.

Diversity indices tended to be lowest at the northern and southern margins of the species' range (Table 3). When summed across loci, the S7, S17 and S31 samples exhibited the most haplotypes. The S7 and S17 samples exhibited relatively high 
haplotypic $(h)$ and nucleotide $(\pi)$ diversities for $C O I$ and $C y t b$, whereas N11 had the highest $h$ and $\pi$ indices for HSP. Diversity indices for ATPs $\alpha$ were greatest in the southernmost samples: $h$ was greatest in S31, and $\pi$ was greatest in S32. Rarefaction estimates, adjusted to the smallest sample size $(N=8)$, identified the greatest allelic richness $\left(a^{\prime}\right)$ and private allelic richness $\left(P_{a}\right)$ in the $\mathrm{S} 7$ sample.

\subsection{Population structure}

The Structure analysis (Fig. 5A) identified two clusters $(K=2)$ that distinguished the NEPR (N13, N11 and N9) and PAR (S31 and S32) populations. Individuals from the SEPR region (S7-S17) were assigned NEPR, PAR, or as mixed genotypes. Because we sampled only two nuclear genes, and experienced missing data due presumably to allelic dropouts, the NEWHYBRIDS analyses were inconclusive in assigning genotypes to F1, F2, Bx, etc. generations (data not reported). Instead, we conducted a BAYESASS analyses with three genes, COI, HSP, and ATPs $\alpha$ (Fig. 5B). Mitochondrial Cytb was completely correlated with $C O I$ and not included. Bayesian deviances calculated with trace files of iterative runs differed less than $0.04 \%$ despite differences in the starting points (random seeds) or number of generations; the analysis with the lowest deviance was portrayed. Although we had limited statistical power to discriminate among genotypic assignments, the vast majority of NEPR and PAR individuals appeared to be "pure" (non-migrants) genotypes. In contrast, the SEPR populations were a combination of EPR non-migrants and PAR $1^{\text {st }}$ - and $2^{\text {nd }}$-generation immigrants. These results clearly illustrated the SEPR as a region of intergradation between NEPR and PAR populations.

The BAYESASS analysis also clarified a pattern in the distribution of heterozygote deficiencies for the nuclear loci. Fixation indices $\left(F_{\text {IS }} \pm\right.$ s.e. $)$ were greatest in the EPR 
Zhang et al. manuscript for Rona volume

$(0.2013 \pm 0.0329)$ samples and less in the PAR $(0.1558 \pm 0.0365)$ samples. As previously noted, allelic dropouts might be responsible for part of these deficiencies, but they are not likely to explain the differences between the NEPR, SEPR and PAR clusters. Allelic dropouts should be relatively homogeneous, unless the samples were affected by differential storage. All the samples were frozen at $-80{ }^{\circ} \mathrm{C}$ for different time-periods, yet the newest (PAR) and the oldest (EPR) samples had the lowest fixation indices. Though we cannot exclude the possibility that some unknown technical problems caused these deficiencies, the elevated $F_{\text {IS }}$ indices might have resulted from Wahlund effects in the SEPR samples. More independent nuclear loci and fresh samples would help to clarify some of these questions.

\subsection{Test for Isolation-by-Distance}

Highly significant correlations (Fig. 4B) existed between pairwise $\Phi_{\mathrm{ST}}$-values and geographical distances for COI (Mantel's $r=0.981, P=0.001), C y t b(r=0.928, P=$ 0.002), and HSP $(r=0.881, P=0.003)$, but not $A T P s \alpha(r=0.298, P=0.0971)$. However, when samples were assigned to their respective ridge axes (NEPR, SEPR, and PAR), stratified Mantel test revealed no significant correlations with geographical distances. These apparent IBD patterns were attributable to hierarchical population structure.

\section{Discussion}

Multilocus analyses revealed that $T$. jerichonana genotypes could be assigned to northern and southern lineages that occupied the NEPR and PAR regions of the southeastern Pacific ridge system. Connecting segments of the SEPR axis represented a 
region of step-clines and intergradation between the two lineages (Fig. 5). The significant cytonuclear disequilibrium (CND) observed between ATPs $\alpha$ and mtDNA genes at SEPR also indicated admixture in this region, although no significance was found at HSP. Latitudinal clines that produced an IBD-like signal were observed, as previously reported for $C O I$ (Audzijonyte and Vrijenhoek, 2010). Cytb exhibited an identical signal because the mitochondrial genes are coupled in the non-recombinant mitochondrial genome. In addition, two independent nuclear genes, $H S P$ and $A T P s \alpha$, also exhibited IBD-like signals, though the slopes of $\Phi_{\mathrm{ST}}$ on latitude were shallower (Fig. 4). Stepping-stone dispersal (SSD) among discrete vent fields could create the IBD-like signals (Slatkin, 1993). Strong selection gradients also could result in a convergence of clines among independent loci (Barton, 1983), although there was no evidence of selection on any locus examined. The geochemical composition of vent effluents can vary greatly on very small spatial scales (Luther et al., 2001), but the extremes of these local conditions are very broad. In contrast, the temperatures and salinities of ambient (non-vent) seawater are relatively homogeneous at depths occupied by $T$. jerichonana $(2235-2747 \mathrm{~m})$.

\subsection{The Refuge/re-invasion hypothesis}

A regional extinction event (or events) followed by secondary invasion of the SEPR axis with $T$. jerichonana colonists from NEPR and PAR refugia could have generated the observed patterns. According to the refuge/re-invasion hypothesis, the NEPR and PAR lineages were temporarily split when the conjoining SEPR populations were extinguished. We can only guess about the geotectonic events that might have led to extinction along this superfast-spreading axis. Evidence for regional instability derives 
from population genetic studies of other vent-restricted animals. For example, SEPR populations of Bathymodiolus thermophilus mussels exhibit similar evidence for reinvasion from NEPR (or GAR) sources, with limited introgression of B. antarcticus genes from the PAR region (Johnson et al., 2013; Plouviez et al., 2013). Re-invasion by other annelids appears to be unidirectional, however. For example, very low levels of genetic diversity in SEPR populations of Riftia pachyptila might have resulted from unidirectional invasion and founder events involving NEPR or GAR immigrants (Coykendall et al., 2011). A PAR refugium may not exist for $R$. pachyptila. In contrast, SEPR populations of Alvinella pompejana are distinct from the NEPR and GAR populations (Hurtado et al., 2004), leading Plouviez et al. (2010) to hypothesize that the lineages split about 1-2 million years ago. SEPR populations of several gastropod limpets also exhibit varying degrees of differentiation that are consistent with secondary invasion and recent range expansions. Together, patterns of genetic diversity in SEPR populations of vent-restricted species support a hypothesis of secondary invasions by NEPR/GAR immigrants and recent range expansions (Plouviez et al., 2009, 2010).

The two cases that differ from this pattern involve admixture between NEPR and PAR sources. Higher genic diversity in SEPR populations of T. jerichonana resulted from re-invasion and admixture between NEPR and PAR lineages. Higher genic diversity in the southern SEPR populations of $B$. thermophilus also appears to be a consequence of hybridization and limited introgression of $B$. antarcticus alleles from the PAR region (Johnson et al., 2013; Plouviez et al., 2013). The time-scales for differentiation between the parental lineages differ greatly, however. Molecular evidence suggests that $B$. thermophilus and B. antarcticus probably split about 4-5 million years (Ma) ago roughly 
coincident with orogeny of the Easter Microplate (Won et al., 2003a); whereas the $T$. jerichonana lineages appear to have split more recently. Divergence between the NEPR and PAR lineages was small and not indicative of species-level differentiation. Only 1-3 mutational steps separated the leading NEPR and PAR allelic haplotypes for each gene. Due to statistical uncertainties, we did not attempt to estimate a divergence time between the two T. jerichonana lineages. However, Plouviez et al. $(2013 ; 2009)$ hypothesized that geotectonic activities in equatorial region during the last $0.5 \mathrm{Ma}$ severed the connections between NEPR and SEPR populations of A. pompejana, B. thermophilus, and possibly other vent species. The confidence intervals for such estimates are large, however, ranging from 0 to $2 \mathrm{Ma}$. Thus, for now it is only safe to conclude that these events were more recent than the orogeny of the Easter Microplate.

\section{Conclusions}

A broad zone of intergradation was identified between lineages of hydrothermal vent tubeworm Tevnia jerichonana. The marginal signal for cytonuclear disequilibrium and the slight divergence between lineages indicated the separation might have happened more recently. We hypothesize that the SEPR region is a demographic sink for $T$.

jerichonana. Like other weedy species, $T$. jerichonana are continuously subjected to local extinction and recolonization events. If local extinction rates exceed recolonization rates, a regional metapopulation will crash. Extinction and recolonization rates will differ among vent species due to their unique life histories, dispersal rates, and susceptibilities to local extinction. Thus, attempts to infer a 'shared' vicariance event (or events) from genetic data might be extremely difficult. Efforts to reconstruct the tectonic history of the SEPR axis and the history of ocean circulation in this region might provide better insights 
Zhang et al. manuscript for Rona volume

into the factors that shaped the diverse population structures of these hydrothermal vent species.

\section{Author's contributions}

HZ, SBJ and VRF conducted DNA sequencing. HZ, RCV, and SBJ performed statistical analyses. RCV conceived of the project and led oceanographic expeditions that collected the samples. HZ and RCV prepared the manuscript.

\section{Acknowledgements}

We thank the captains and crews of the R/V Atlantis and the pilots of the DSV Alvin for their expert help. Corinna Breusing provided helpful comments on the manuscript. NSF grants OCE8917311, OCE9212771, OCE9302205, OCE9633131, OCE9910799, OCE0241613 to RCV funded oceanographic expeditions conducted between 1989 and 2005. HZ was supported by Monterey Bay Aquarium Research Institute with a postdoctoral fellowship funded by The David and Lucile Packard Foundation.

\section{References}

Anderson, E.C., Thompson, E.A., 2002. A model-based method for identifying species hybrids using multilocus genetic data. Genetics 160, 1217-1229.

Antao, T., Lopes, A., Lopes, R., Beja-Pereira, A., 2008. LOSITAN: a workbench to detect molecular adaptation based on a Fst-outlier method. BMC Informatics 9, 323.

Arnold, M.L., 1997. Natural Hybridization and Evolution. Oxford University Press, Oxford, UK.

Asmussen, M.A., Basten, C.J., 1994. Sampling theory for cytonuclear disequilibria. Genetics 138, 1351-1363.

Audzijonyte, A., Vrijenhoek, R., 2010. When gaps really are gaps: statistical phylogeography of hydrothermal vent invertebrates. Evolution 64, 2369-2384.

Bandelt, H., Forster, P., Rohl, A., 1999. Median-joining networks for inferring 
intraspecific phylogenies. Molecular Biology and Evolution 16, 37-48.

Barton, N.H., 1980. The hybrid sink effect. Heredity 44, 277.

Barton, N.H., 1983. Multilocus clines. Evolution 37, 454-471.

Barton, N.H., Hewitt, G.M., 1985. Analysis of hybrid zones. Annual Review of Ecology and Systematics 16, 113-148.

Basten, C.J., Asmussen, M.A., 1997. The exact test for cytonuclear disequilibria. Genetics 146, 1165-1171.

Beaumont, M.A., Nichols, R.A., 1996. Evaluating loci for use in the genetic analysis of population structure. Proceedings of the Royal Society of London: Biological Sciences 263, 1619-1626.

Black, M.B., Halanych, K.M., Maas, P.A.Y., Hoeh, W.R., Hashimoto, J., Desbruyères, D., Lutz, R.A., Vrijenhoek, R.C., 1997. Molecular systematics of vestimentiferan tube worms from hydrothermal vents and cold-water seeps. Marine Biology 130, 141-149.

Boore, J., Brown, W., 2000. Mitochondrial genomes of Galathealinum, Helobdella and Platynereis: sequence and gene arrangement comparisons indicate that Pogonophora is not a phylum and Annelida and Arthropoda are not sister taxa. Molecular Biology and Evolution 17, 87-106.

Coykendall, D.K., Johnson, S.B., Karl, S.A., Lutz, R.A., Vrijenhoek, R.C., 2011. Genetic diversity and demographic instability in Riftia pachyptila tubeworms from eastern Pacific hydrothermal vents. BMC Evolutionary Biology 11, 96 (11 pages).

Elphinstone, M.S., Hinten, G.N., Anderson, M.J., Nock, C.J., 2003. An inexpensive and high-throughput procedure to extract and purify total genomic DNA for population studies. Molecular Ecology Notes 3, 317-320.

Endler, J., 1977. Geographic Variation, Speciation and Clines. Princeton University Press, Princeton (NJ).

Endler, J.A., 1982. Problems in distinguishing historical from ecological factors in biogeography. American Zoologist 22, 441-452.

Evanno, G., Regnaut, S., Goudet, J., 2005. Detecting the number of clusters of individuals using the software STRUCTURE: a simulation study. Molecular Ecology 14, 2611-2620. 
Excoffier, Lischer, H., 2009. Arlequin ver 3.5: an integrated software package for population genetics data analysis. Swiss Institute of Bioinformatics, pp. 1-174.

Gardner, J.P.A., 1997. Hybridization in the sea. Advances in Marine Biology 31, 1-78.

Harrison, R.G., 1993. Hybrid Zones and the Evolutionary Process. Oxford University Press, New York.

Hurtado, L.A., Lutz, R.A., Vrijenhoek, R.C., 2004. Distinct patterns of genetic differentiation among annelids of eastern Pacific hydrothermal vents. Molecular Ecology 13, 2603-2615.

Huxley, J.S., 1938. Clines: an auxilliary taxonomic principle. Nature 142, 219-220.

Jarman, S.N., Ward, R.D., Elliott, N.G., 2002. Oligonucleotide primers for PCR amplification of coelomate Introns. Marine Biotechnology 4, 347-355.

Johnson, S.B., Won, Y.-J., Harvey, J.B., Vrijenhoek, R.C., 2013. A hybrid zone between Bathymodiolus mussel lineages from eastern Pacific hydrothermal vents. BMC Evolutionary Biology 13, 21.

Jollivet, D., 1993. Distribution et évolution de la faune associée aux sources hydrothermales profondes à $13^{\circ} \mathrm{N}$ sur la dorsale du Pacifique oriental: le cas particulier des polychètes Alvinellidae, Thèse de doctorat nouveau régime Dissertation, Université de Bretagne Occidentale, Brest, France, 357 Pages.

Kalinowsky, S., 2005. HP-RARE 1.0: a computer program for performing rarefaction on measures of allelic richness. Molecular Ecology Notes 5, 187-189.

Kearse, M., Moir, R., Wilson, A., Stones-Havas, S., Cheung, M., Sturrock, S., Buxton, S., Cooper, A., Markowitz, S., Duran, C., Thierer, T., Ashton, B., Mentjies, P., \& Drummond, A. 2012. Geneious Basic: an integrated and extendable desktop software platform for the organization and analysis of sequence data. Bioinformatics 28, 1647-1649.

Luther, G.W., Rozan, T.F., Taillefert, M., Nuzzio, D.B., Di Meo, C., Shank, T.M., Lutz, R.A., Cary, S.C., 2001. Chemical speciation drives hydrothermal vent ecology. Nature 410, 813-816.

Lyngsø, R.B., Song, Y.S., Hein, J., 2005. Minimum recombination histories by branch and bound. Workshop on Algorithms in Bioinformatics, 239-250.

Marsh, A.G., Mullineaux, L.S., Young, C.M., Manahan, D.T., 2001. Larval dispersal 
potential of the tubeworm Riftia pachyptila at deep-sea hydrothermal vents. Nature 411, 77-80.

Meirmans, P.G., 2012. The trouble with isolation by distance. Molecular Ecology 21, 2839-2846.

Meirmans, P.G., 2014. Nonconvergence in Bayesian estimation of migration rates. Molecular Ecology Resources 14, 726-733.

Meirmans, P.G., van Teinderen, P., 2004. genotype and genodive: two programs for the analysis of genetic diversity of asexual organisms. Molecular Ecology Notes 4, 792794.

Mullineaux, L.S., Fisher, C.R., Peterson, C.H., Schaeffer, S.W., 2000. Tubeworm succession at hydrothermal vents: use of biogenic cues to reduce habitat selection error? Oecologia 123, 275-284.

Mullineaux, L.S.L., Le Bris, N.N., Mills, S.W.S., Henri, P.P., Bayer, S.R.S., Secrist, R.G.R., Siu, N.N., 2012. Detecting the influence of initial pioneers on succession at deep-sea vents. PLoS One 7, e50015-e50015.

Nelson, K., Fisher, C., 2000. Absence of cospeciation in deep-sea vestimentiferan tube worms and their bacterial endosymbionts. Symbiosis 28, 1-15.

O'Mullan, G.D., Maas, P.A.Y., Lutz, R.A., Vrijenhoek, R.C., 2001. A hybrid zone between hydrothermal vent mussels (Bivalvia: Mytilidae) from the Mid-Atlantic Ridge. Molecular Ecology 10, 2819-2831.

Orsini, L., Vanoverbeke, J., Swillen, I., Mergeay, J., De Meester, L., 2013. Drivers of population genetic differentiation in the wild: isolation by dispersal limitation, isolation by adaptation and isolation by colonization. Molecular Ecology 22, 59835999.

Piyamongkol, W., Bermúdez, M.G., Harper, J.C., Wells, D., 2003. Detailed investigation of factors influencing amplification efficiency and allele drop-out in single cell PCR: implications for preimplantation genetic diagnosis. Molecular Human Reproduction $9,411-420$.

Plouviez, S., Faure, B., Le Guen, D., Lallier, F.H., Bierne, N., Jollivet, D., 2013. A new barrier to dispersal trapped old genetic clines that escaped the easter microplate tension zone of the pacific vent mussels. PLoS One 8, e81555-e81555. 
Plouviez, S., Le Guen, D., Lecompte, O., Lallier, F., Jollivet, D., 2010. Determining gene flow and the influence of selection across the equatorial barrier of the East Pacific Rise in the tube-dwelling polychaete Alvinella pompejana. BMC Evolutionary Biology 10, 220.

Plouviez, S., Shank, T.M., Faure, B., Daguin-Thiebaut, C., Viard, F., Lallier, F.H., Jollivet, D., 2009. Comparative phylogeography among hydrothermal vent species along the East Pacific Rise reveals vicariant processes and population expansion in the South. Molecular Ecology 18, 3903-3917.

Pritchard, J.K., Stephens, M., Donnelly, P., 2000. Inference of population structure using multilocus genotype data. Genetics 155, 945-959.

Raymond, M., Rousset, F., 1995. GENEPOP (Ver. 1.2): population genetics software for exact tests and ecumenicism. Journal of Heredity 86, 248-249.

Shank, T.M., Fornari, D.J., Von Damm, K.L., Lilley, M.D., Haymon, R.M., Lutz, R.A., 1998. Temporal and spatial patterns of biological community development at nascent deep-sea hydrothermal vents (950'N East Pacific Rise). Deep-Sea Research II 45, 465-515.

Slatkin, M., 1993. Isolation by distance in equilibrium and non-equilibrium populations. Evolution 47, 264-279.

Stephens, M., Smith, N.J., Donnelly, P., 2001. A new statistical method for haplotype reconstruction from population data. American Journal of Human Genetics 68, 978989.

Vrijenhoek, R.C., 2010. Genetic diversity and connectivity of deep-sea hydrothermal vent metapopulations. Molecular Ecology 19, 4391-4411.

Wickham, H., 2009. ggplot2: elegant graphics for data analysis. Springer, New York.

Wilson, G., Rannala, B., 2003. Bayesian inference of recent migration rates using multilocus genotypes. Genetics 163, 1177-1191.

Won, Y., Young, C.R., Lutz, R.A., Vrijenhoek, R.C., 2003a. Dispersal barriers and isolation among deep-sea mussel populations (Mytilidae: Bathymodiolus) from eastern Pacific hydrothermal vents. Molecular Ecology 12, 169-184.

Won, Y.-J., Hallam, S.J., O'Mullan, G.D., Vrijenhoek, R.C., 2003b. Cytonuclear disequilibrium in a hybrid zone involving deep-sea hydrothermal vent mussels of the 
genus Bathymodiolus. Molecular Ecology 12, 3185-3190.

Wright, S., 1943. Isolation by distance. Genetics 28, 114-138.

Zhang, G., Fang, X., Guo, X., Li, L., Luo, R., Xu, F., Yang, P., Zhang, L., Wang, X., Qi, H., Xiong, Z., Que, H., Xie, Y., Holland, P.W.H., Paps, J., Zhu, Y., Wu, F., Chen, Y., Wang, J., Peng, C., Meng, J., Yang, L., Liu, J., Wen, B., Zhang, N., Huang, Z., Zhu, Q., Feng, Y., Mount, A., Hedgecock, D., Xu, Z., Liu, Y., Domazet-Loso, T., Du, Y., Sun, X., Zhang, S., Liu, B., Cheng, P., Jiang, X., Li, J., Fan, D., Wang, W., Fu, W., Wang, T., Wang, B., Zhang, J., Peng, Z., Li, Y., Li, N., Wang, J., Chen, M., He, Y., Tan, F., Song, X., Zheng, Q., Huang, R., Yang, H., Du, X., Chen, L., Yang, M., Gaffney, P.M., Wang, S., Luo, L., She, Z., Ming, Y., Huang, W., Zhang, S., Huang, B., Zhang, Y., Qu, T., Ni, P., Miao, G., Wang, J., Wang, Q., Steinberg, C.E.W., Wang, H., Li, N., Qian, L., Zhang, G., Li, Y., Yang, H., Liu, X., Wang, J., Yin, Y., Wang, J., 2012. The oyster genome reveals stress adaptation and complexity of shell formation. Nature 490, 49-54. 
Zhang et al. manuscript for Rona volume

\section{Figure Legends}

Figure 1. Tevnia jerichonana collected from Alvin dive A4093. Photo by G.W. Rouse.

Figure 2. Allelic frequencies in Tevnia jerichonana samples. (A) Southeastern Pacific vent localities: present samples [blue, yellow and red dots]; records for T. jerichonana but no samples [gray triangles]; no records of T. jerichonana [white dots]. (B) Allelic frequencies at four loci. Black wedges represent frequencies of private alleles, and yellow wedges represent singletons.

Figure 3. Haplotype networks: (A) Cytochrome-c-oxidase subunit-I; (B) Cytochrome b; (C) Heat-shock protein; (D) ATP synthetase subunit $\alpha$. Sizes of circles correspond to abundance of each sequence. Numbers in or adjacent to each circle denote the haplotypic allele. Each link indicates a single mutation, and the slash in panel B indicates a mutation that was not observed.

Figure 4. Clines and IBD analysis. (A) Frequencies of leading 'northern' alleles versus degrees $\mathrm{N}$ latitude. (B) Correlation of pairwise $\Phi_{\mathrm{ST}}$ 's with geographic distances among the sample localities. Negative $\Phi_{\mathrm{ST}}$ values (Supplementary Table 1) were set to zero.

Coefficients of determination $\left(R^{2}\right)$ and significance of correlations ( $P$-values) are listed in boxes.

Figure 5A. STRUCTURE analysis of multilocus genotypes for the seven sample localities. Blue bars denote probability that an individual has an EPR genotype and red bars denote 
probability that an individual has a PAR genotype. 5B. Posterior probabilities of BAYESASS assignments of migrant ancestries. Dark blue bars indicate non-migrant, medium blue indicate $1^{\text {st }}$ generation, and light blue indicates $2^{\text {nd }}$ generation EPR immigrants. Red bars indicate non-migrant, dark pink bars indicate $1^{\text {st }}$ generation, and light pink bars indicate $2^{\text {nd }}$ generation PAR genotypes. 
Zhang et al. manuscript for Rona volume

\section{Tables}

Table 1. Coordinates and depths for Tevnia jerichonana samples.

\begin{tabular}{lrrlll}
\hline Locality & Latitude $^{1}$ & Longitude $^{\mathrm{a}}$ & Depths (m) & Alvin dive numbers & Sampling dates \\
\hline N13 & 12.82 & -103.95 & $2630-2636$ & A2227-A2229 & Jun-90 \\
N11 & 11.42 & -103.78 & $2516-2522$ & A2225-A2226 & Jun-90 \\
N9 & 9.28 & -104.22 & $2505-2583$ & A2351, A2365, A2498 A2499, A2502, & Apr-91, Oct-94 \\
S7 & -7.43 & -104.78 & $2737-2747$ & A3320-A3322 & Dec-98 \\
S17 & -17.43 & -113.20 & 2582 & A3328 & Jan-99 \\
S31 & -31.15 & -111.93 & $2334-2338$ & A3337-A3339, A4094 & Jan-99, Mar-05 \\
S32 & -31.87 & -112.05 & $2235-2336$ & A3341, A4092-A4093 & Mar-05 \\
\hline
\end{tabular}

${ }^{a}$ Coordinates: negative numbers indicate south latitudes and west longitudes.

${ }^{\mathrm{b}}$ Dive logs: http://www.marine.whoi.edu/divelog.nsf/By Dive Number/Date?OpenView

Table 2. DNA primers, coding information, and fragment lengths included in analyses.

\begin{tabular}{|c|c|c|c|c|c|}
\hline Locus & Product & Length & Primer & Primer Sequence $\left(5^{\prime}-3^{\prime}\right)$ & Ref. $^{\text {a }}$ \\
\hline \multirow[t]{2}{*}{ COI } & \multirow{2}{*}{$\begin{array}{l}\text { Cytochrome-c- } \\
\text { oxidase subunit } \\
\text { I }\end{array}$} & \multirow[t]{2}{*}{$775 \mathrm{bp}$} & COIF & TCMACTAATCAYAARGAYATTGGNAC & 1 \\
\hline & & & COIR & CCDCTTAGWCCTARRAARTGTTGNGG & 1 \\
\hline \multirow[t]{2}{*}{$C y t b$} & \multirow[t]{2}{*}{ Cytochrome B } & \multirow[t]{2}{*}{$320 \mathrm{bp}$} & $424 \mathrm{~F}$ & GGWTAYGTWYTWCCWTGRGGWCARAT & 2 \\
\hline & & & $876 \mathrm{R}$ & $\begin{array}{l}\text { GCRTAWGCRAAWARRAARTAYCAYTCWG } \\
\text { G }\end{array}$ & 2 \\
\hline \multirow[t]{3}{*}{$H S P$} & \multirow{3}{*}{$\begin{array}{l}\text { Heat shock } \\
\text { protein-70 }\end{array}$} & \multirow{3}{*}{$\begin{array}{l}173 \mathrm{bp} \\
75 \text { exon-1 } \\
98 \text { intron }\end{array}$} & HSP242F1 & GGGCGTCGCTTCGACGAACA & 4 \\
\hline & & & HSP922R1 & CCTGGCGCTGGGAGTCGTTG & 4 \\
\hline & & & HSP_R2_tv & AAGTAGGCGGGCACGGTGAC & 4 \\
\hline \multirow[t]{4}{*}{$A T P s \alpha$} & \multirow{4}{*}{$\begin{array}{l}\text { ATP synthetase } \\
\text { subunit } \alpha\end{array}$} & \multirow{4}{*}{$\begin{array}{l}281 \mathrm{bp} \\
\text { all intron }\end{array}$} & ATPsa_F1 & GAGCCMATGCAGACTGGTATTAAGGCYGT & 3 \\
\hline & & & ATPsa_R1 & AACTTNGMGAAGACCAACTACTACCACAG & 3 \\
\hline & & & ATPsa_F2_tv & CGACAGTCTCGTGCCAATTG & 4 \\
\hline & & & ATPsa_R2_tv & AATAGCAATGGCAGTCTTGC & 4 \\
\hline
\end{tabular}

${ }^{a}$ References: 1. (Nelson and Fisher, 2000); 2. (Boore and Brown, 2000); 3. (Jarman et al., 2002); 4. present study. 
Table 3. Genic diversity indices for Tevnia jerichonana samples from seven East Pacific Rise vent localities.

\begin{tabular}{|c|c|c|c|c|c|c|c|}
\hline \multirow[b]{2}{*}{ Indices ${ }^{\mathrm{a}}$} & \multicolumn{7}{|c|}{ Localities } \\
\hline & N13 & N11 & N9 & S7 & S17 & S31 & S32 \\
\hline $\operatorname{COI}(N)$ & (28) & (14) & (24) & (31) & (24) & (40) & (20) \\
\hline$S$ & 0 & 2 & 5 & 7 & 4 & 3 & 3 \\
\hline$H$ & 1 & 3 & 5 & 8 & 5 & 3 & 3 \\
\hline$h$ & 0 & 0.275 & 0.377 & 0.609 & 0.630 & 0.273 & 0.353 \\
\hline$\pi$ & 0 & 0.286 & 0.493 & 1.346 & 1.163 & 0.427 & 0.468 \\
\hline$a^{\prime}$ & 1 & 2.143 & 2.565 & 3.548 & 2.991 & 1.996 & 2.207 \\
\hline $\mathrm{Pa}$ & 0.000 & 1.143 & 1.232 & 1.361 & 0.848 & 0.071 & 0.301 \\
\hline Cytb (N) & (28) & (19) & (25) & (26) & (31) & (41) & (21) \\
\hline$S$ & 3 & 1 & 6 & 5 & 4 & 4 & 4 \\
\hline$H$ & 4 & 2 & 5 & 4 & 3 & 3 & 3 \\
\hline$h$ & 0.458 & 0.351 & 0.637 & 0.588 & 0.551 & 0.342 & 0.267 \\
\hline$\pi$ & 0.492 & 0.351 & 0.920 & 1.702 & 1.634 & 0.722 & 0.467 \\
\hline$a^{\prime}$ & 2.501 & 1.915 & 3.274 & 2.809 & 2.440 & 2.192 & 2.010 \\
\hline$P a$ & 0.598 & 0.006 & 1.032 & 0.837 & 0.456 & 0.596 & 0.629 \\
\hline$H S P(N)$ & (34) & (8) & (34) & (36) & (54) & (58) & (36) \\
\hline$S$ & 2 & 3 & 3 & 8 & 7 & 9 & 6 \\
\hline$H$ & 3 & 4 & 4 & 10 & 10 & 14 & 7 \\
\hline$h$ & 0.398 & 0.750 & 0.620 & 0.710 & 0.670 & 0.839 & 0.786 \\
\hline$\pi$ & 0.424 & 1.036 & 0.733 & 1.411 & 1.152 & 1.466 & 1.316 \\
\hline$F_{\mathrm{IS}}^{\mathrm{b}}$ & 0.416 & 0.700 & 0.150 & 0.459 & 0.173 & 0.139 & 0.010 \\
\hline$a^{\prime}$ & 2.329 & 4.000 & 2.990 & 4.282 & 3.904 & 5.047 & 4.367 \\
\hline$P a$ & 0.000 & 0.804 & 0.235 & 0.799 & 0.781 & 1.943 & 0.743 \\
\hline$A T P s \alpha(N)$ & (30) & (16) & (30) & (46) & (40) & (68) & (36) \\
\hline$S$ & 1 & 1 & 2 & 1 & 1 & 5 & 4 \\
\hline$H$ & 2 & 2 & 3 & 2 & 2 & 5 & 4 \\
\hline$h$ & 0.370 & 0.500 & 0.570 & 0.348 & 0.409 & 0.403 & 0.211 \\
\hline$\pi$ & 0.370 & 0.500 & 0.644 & 0.348 & 0.409 & 0.737 & 0.376 \\
\hline$F_{\mathrm{IS}}$ & 0.468 & 1.000 & 0.306 & 0.506 & 0.395 & 0.347 & 0.481 \\
\hline$a^{\prime}$ & 1.916 & 1.997 & 2.461 & 1.884 & 1.944 & 2.524 & 1.844 \\
\hline $\mathrm{Pa}$ & 0.000 & 0.000 & 0.469 & 0.000 & 0.000 & 1.177 & 0.498 \\
\hline Totals & & & & & & & \\
\hline Haplotypes & 10 & 11 & 17 & 24 & 20 & 25 & 17 \\
\hline Singletons $\mathrm{s}^{\mathrm{c}}$ & 2 & 2 & 4 & 6 & 3 & 1 & 1 \\
\hline Richness $\left(a^{\prime}\right)^{\mathrm{d}}$ & 1.940 & 2.510 & 2.820 & 3.130 & 2.820 & 2.940 & 2.610 \\
\hline Privates $(P a)^{\mathrm{e}}$ & 0.150 & 0.490 & 0.740 & 0.750 & 0.520 & 0.950 & 0.540 \\
\hline
\end{tabular}

${ }^{a}$ Diversity indices: $N$, number of sequences; $S$, number of polymorphic sites; $H$, number of haplotypes (i.e. alleles); $H$, haplotype diversity; $\pi$, mean number of differences between pairs of sequences;

b Significant values indicated in bold.

c Singletons (alleles observed only once).

${ }^{d}$ Rarefaction estimate of allelic richness for the for genes, adjusted to minimum sample size of 8 .

e Privates allelic richness for the four genes, adjusted to minimum sample size of 8 . 
Fig. 1

A

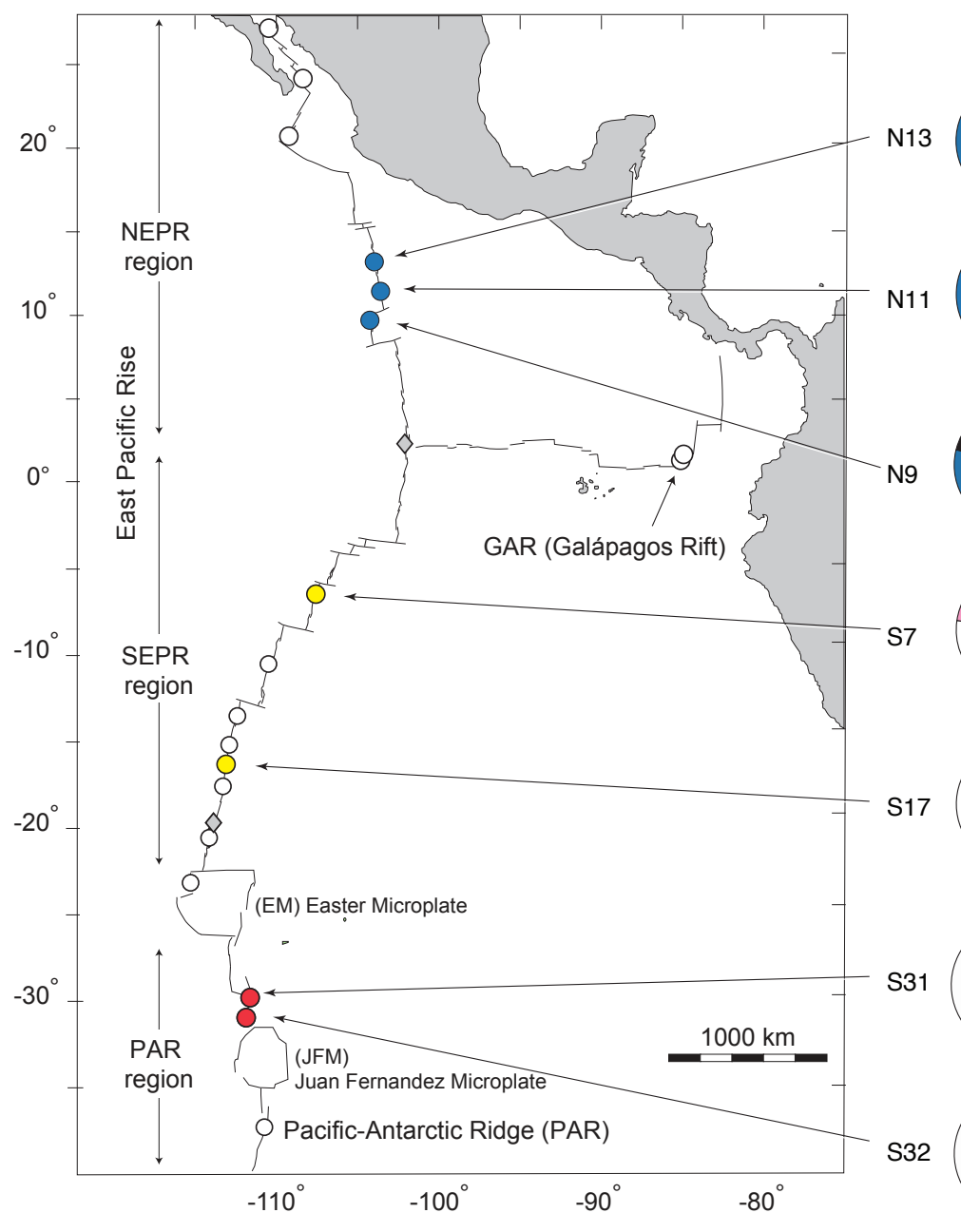

B
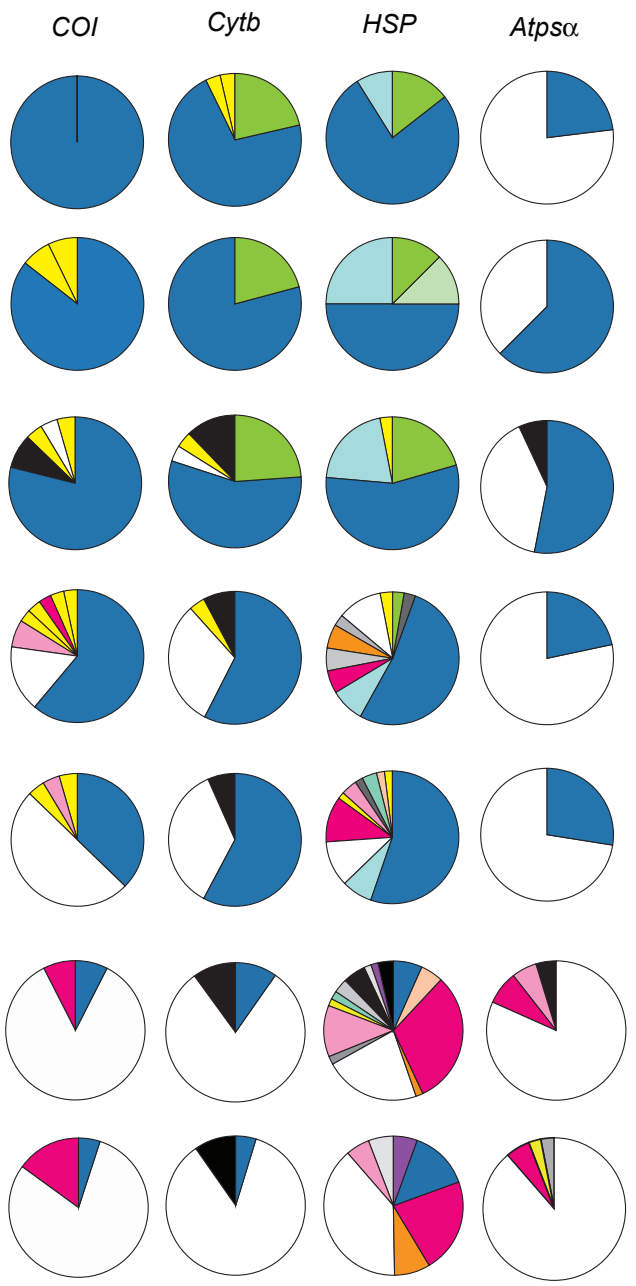

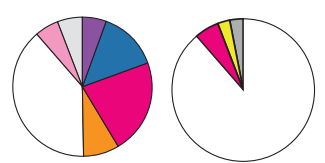

Fig. 2 



ATPs $\alpha$



Fig. 3 
A

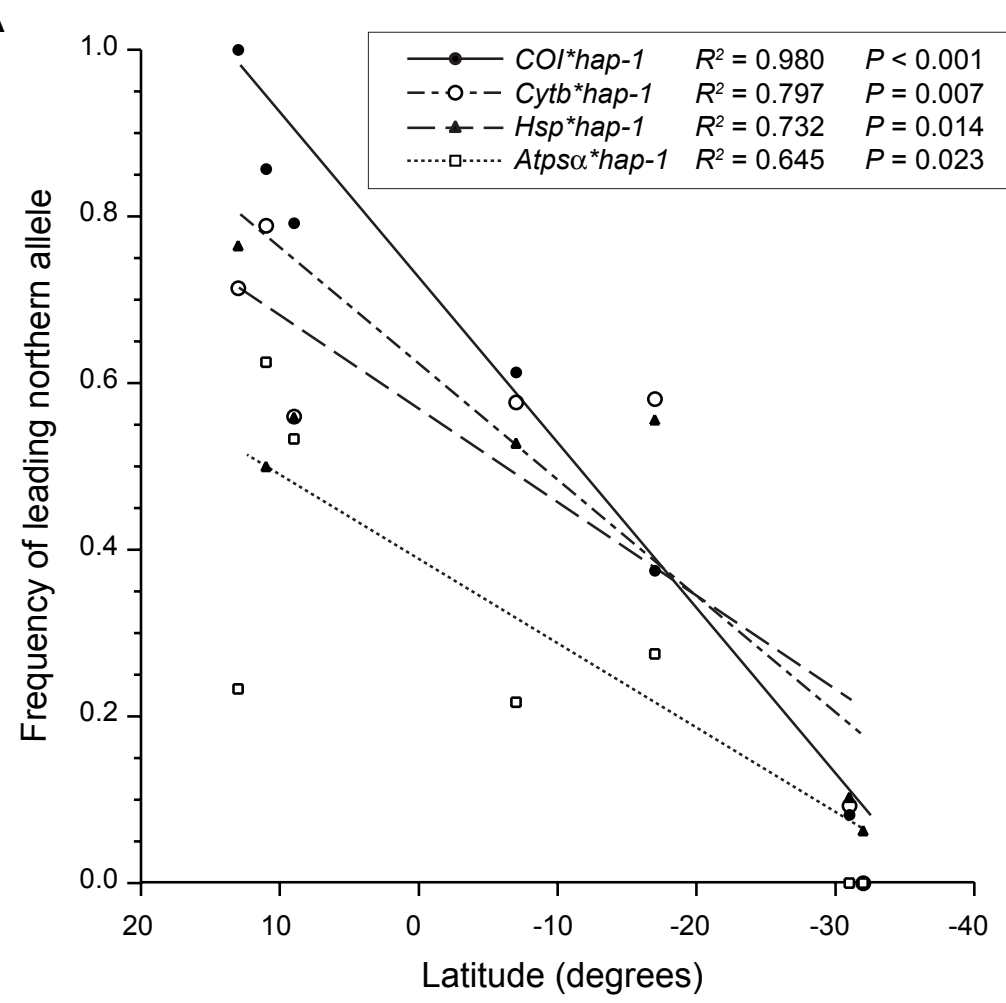

B

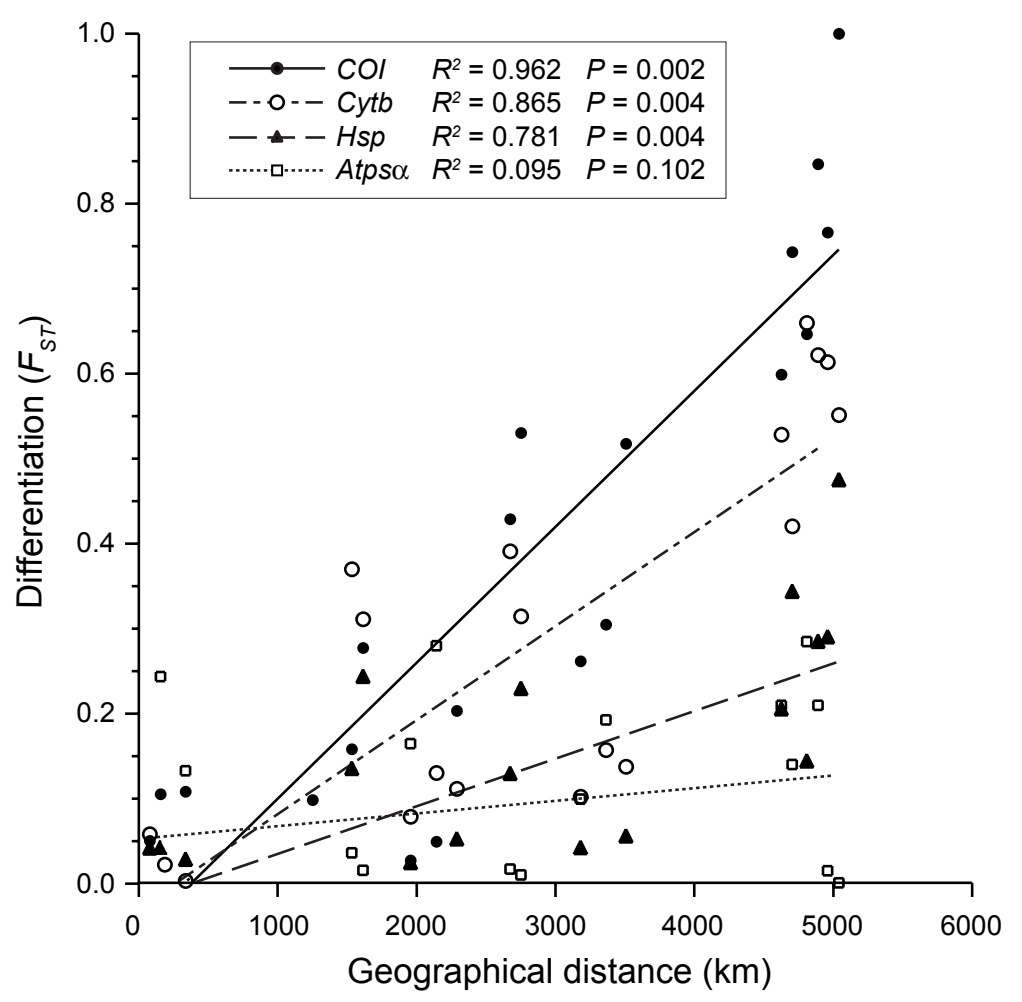

FIGURE 4 


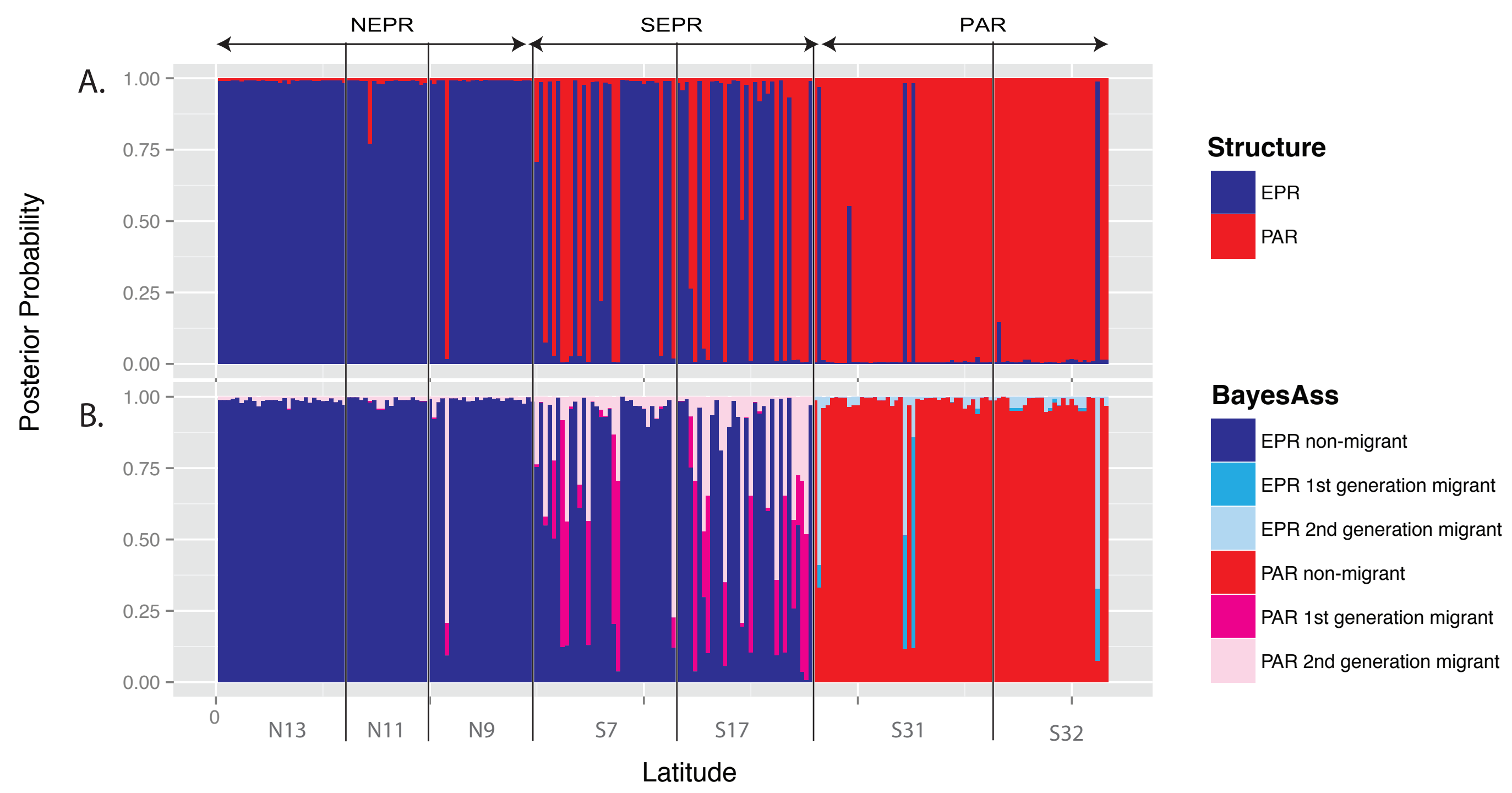

